\title{
Effects of Tripterygium glycoside treatment on experimental autoimmune encephalomyelitis
}

\author{
JIANMIN QIU $^{1}, \mathrm{XUELIAN} \mathrm{YOU}^{1}$ and GANG WU ${ }^{2}$ \\ ${ }^{1}$ Department of Internal Medicine Neurology, Fujian Putian First Hospital, Putian, Fujian 351100; \\ ${ }^{2}$ Department of Internal Medicine Neurology, The First Affiliated Hospital of Fujian Medical University, \\ Fuzhou, Fujian 350004, P.R. China
}

Received July 29, 2016; Accepted July 17, 2017

DOI: $10.3892 / \mathrm{mmr} .2017 .7627$

\begin{abstract}
Experimental autoimmune encephalomyelitis (EAE) is an autoimmune disease mediated by $\mathrm{CD}^{+} \mathrm{T}$ cells. It is characterized by mononuclear cell infiltration around the small blood vessels in the central nervous system (CNS). Previous investigations have found that apoptosis is associated with the occurrence and development of autoimmune disease, and that mononuclear cell apoptosis and clearance from the CNS is one of the repair mechanisms of EAE. Tripterygium wilfordii glycoside (TWP) is an organic matter isolated from Tripterygium wilfordii, which has anti-inflammatory and immunosuppressive effects. In the present study, male Lewis rats were randomly divided into a normal control, EAE and TWP groups. Rats in EAE and TWP groups received injections of emulsified EAE antigen (myelin protein) at two points on the footpad while control group received PBS. The TWP group was then treated with TWP daily for 21 days. Symptoms and nerve function scores were observed and evaluated. Specimens of blood, brain and spinal cord were collected for further pathological examination, Tunel assay, ELISA and immunohistochemistry were performed to examine the effect of TWP on the onset of EAE, and changes in CNS inflammatory infiltration, cell apoptosis, and the expression of nuclear factor (NF)- $\kappa$ B P65 and interleukin (IL)-2. The results showed that the TWP treatment group exhibited decreased EAE and delayed onset, compared with the control. The clinical symptoms were significantly reduced and alleviation of inflammatory cell infiltration was observed. Compared with the EAE group, a higher inflammatory cell apoptotic rate, and reduced serum levels of IL-2 and NF- $\kappa$ B p65-positive cells were observed in the TWP treatment group. Therefore, TWP effectively inhibited EAE via the inhibition
\end{abstract}

Correspondence to: Dr Jianmin Qiu, Department of Internal Medicine Neurology, Fujian Putian First Hospital, 389 Chengxiang Longde Wells, Putian, Fujian 351100, P.R. China

E-mail: qiujianminion@163.com

Key words: experimental autoimmune encephalomyelitis, Tripterygium wilfordii glycoside, inflammatory cell infiltration, apoptosis of CNS inflammatory cell infiltration, enhancement of inflammatory cell apoptosis, and downregulation of the expression of $\mathrm{NF}-\kappa \mathrm{B}$ and IL-2.

\section{Introduction}

Experimental autoimmune encephalomyelitis (EAE) is an autoimmune disease mediated by $\mathrm{CD}^{+} \mathrm{T}$ cells. It is used as a classical experimental animal model for the investigation of multiple sclerosis (MS) as it has similar features in terms of clinical manifestation, pathological characteristics and immune abnormalities (1). Previous studies have shown that apoptosis is closely associated with the occurrence, development and prognosis of autoimmune disease. The reduction of infiltrated mononuclear cells from the CNS in the form of apoptosis is one of the repair mechanisms of EAE (2). Tripterygium wilfordii belongs to the celastraceae family of plants, and exhibits anti-inflammatory, immunosuppressive and antitumor effects. Tripterygium wilfordii glycoside (TWP) is isolated from the Tripterygium wilfordii using organic solvent (3). Several effective ingredients of Tripterygium wilfordii have been widely used clinically for rheumatoid arthritis, systemic lupus erythematosus, and nephrotic syndrome, which have demonstrated beneficial effects (4). Several experiments have confirmed that Tripterygium wilfordii can inhibit lymphocyte proliferation through inducing $\mathrm{T}$ cell apoptosis (5). The present study established an EAE model using Lewis rats, examined the therapeutic effect of TWP on EAE and determined its possible mechanism. This may provide a valuable theoretical basis for the clinical application of TWP in the treatment of MS.

\section{Materials and methods}

Experimental animals. A total of 30 male Lewis rats, aged 6-8 weeks old and weighing 150-180 g, were provided by Shanghai Shiper Shall Kay Laboratory Animal Co., Ltd. (Shanghai, China; license no. SCXK 2008-001). The animals were fed in the laboratory of the Animal Center of Fujian Medical University (Fujian, China) and randomly divided into a normal control group $(n=10)$, model group (EAE; $n=10)$ and TWP treatment group (TWP; $n=10$ ). The rats were housed separately at room temperature, 50-65\% humidity, on a 12-h light/dark cycle and were given access to water and food 
ad libitum. The study was approved by the Ethics Committee of Fujian Medical University (Fujian, China).

Instruments and reagents. The surgical instruments, homogenizer, mortar, infusion needle and Freund's complete adjuvant were provided by Sigma-Aldrich; Merck KGaA (Darmstadt, Germany). The pertussis vaccine (BPV) was purchased from the Shanghai Institute of Biological Products of the Ministry of Health (Shanghai, China; $1 \mathrm{ml}$ containing $\sim 2 \times 10^{10}$ bacteria). An in situ apoptosis detection kit was purchased from Roche Diagnostics (Basel, Switzerland). Proteinase K and BCIP/NBT developing solution were provided by Beijing Huamei Biological Engineering Company (Beijing, China). Nuclear solid red dye solution was provided by Fuzhou New Biotechnology Company (Fuzhou, China). Rabbit anti-rat NF-кB p65 antibody was purchased from Cell Signaling Technology, Inc. (Danvers, MA, USA). The SABC kit was from Wuhan Boster Biotechnology, Ltd. (Wuhan, China). The IL-2 ELISA kit (K4800-100) was from Abnova (Taipei, Taiwan). TWP (10 mg/section; batch no. 101003) was produced by Fujian Huitian Biological Pharmaceutical Co., Ltd. (Fujian, China).

Animal model preparation. Myelin protein (MBP; $0.5 \mathrm{mg}$ ) was dissolved in $2 \mathrm{ml}$ of $0.1 \mathrm{~mol} / \mathrm{l}$ PBS solution, and then mixed with $2 \mathrm{ml}$ Freund's complete adjuvant to form the EAE antigen emulsion. The Lewis rats were anesthetized via $10 \%$ chloral hydrate celiac injection $(350 \mathrm{mg} / \mathrm{kg})$. Subsequently, $0.4 \mathrm{ml}$ antigen emulsion was injected into the rats in the EAE and TWP groups at two points on the footpad of each hindpaw, with the rats in the control group receiving PBS instead.

Drug therapy. TWP was dissolved in $10 \%$ glucose, which was fed to the rats in the TWP group at $10 \mathrm{mg} / \mathrm{kg} / \mathrm{day}$. The rats in the model and control group received an equal volume of $10 \%$ glucose daily for 21 days.

Observation of symptoms and nerve function scores. The activity and weights of the rats were examined daily. A five-point scoring method was used to evaluate the neurological function of the rats (6): 0 , normal; 1 , tail weakness; 2 , tail unstressing; 3, bilateral posterior paresis (partial paralysis); 4 , hind leg complete paralysis with urinary incontinence; 5 , succumbed or moribund. The mean score was obtained from the sum of the scores divided by the number of rats.

Specimen collection. In the EAE and TWP groups, the rats with neurological functions scores $>4$, or with continuation of symptoms for 3 days without aggravation, were considered to beat peak EAE and the rats were sacrificed. The rats in the control group were sacrificed on day 21 . Blood $(1.5 \mathrm{ml})$ from the heart was collected and stored at $-20^{\circ} \mathrm{C}$. The brain and spinal cord were removed, fixed in $4 \%$ paraformaldehyde and embedded in paraffin at room temperature overnight. The parietal lobe of the brain, cerebellar brainstem, cervical enlargement and intumescentia lumbalis were sectioned up to $1 \mathrm{~cm}^{3}$ for hematoxylin and eosin (H\&E) staining.

Pathological examination. The numbers of lesions were counted under microscope (CX41; Olympus Corporation, Tokyo, Japan) following H\&E staining. Elongated cells or the infiltration of $>20$ inflammatory cells were defined as an inflammatory focus. The parietal lobe of the brain, cerebellum brainstem, cervical enlargement and intumescentia lumbalis from each rat were examined. The numbers of lesions in five sections from each region were calculated and combined as the number of inflammatory foci in the rat.

TUNEL assay. The first lumbar spinal cord tissue sections from the TWP group and EAE group were dewaxed and hydrated. Following the addition of proteinase K solution $(20 \mu \mathrm{g} / \mathrm{ml})$, TUNEL reaction mixture $(25 \mu \mathrm{l})$, Counter-AP solution $(50 \mu \mathrm{l})$ and NBT/BCIP (50-100 $\mu \mathrm{l})$ were added, and the section was stained again in nuclear fast red. The section was observed following sealing and drying. A total of 5 visual fields containing sleeve-type changes were selected for the calculation of inflammatory cell infiltration around the blood vessel. Nuclei stained black indicated apoptotic cells. The apoptotic rate of the infiltrated inflammatory cells was calculated as the number of apoptotic cells/number of infiltrated inflammatory cells, with data presented as the mean \pm standard error of mean.

ELISA.The ratIL-2ELISA kit(K4800-100) was purchased from Guangrui Bio (Abnova). Briefly, the plasma samples from rats were added into the microplate pre-coated with IL-2-capture antibody and incubated at $36^{\circ} \mathrm{C}$ for $90 \mathrm{~min}$. Following washing with PBS, the plate was filled with biotinylatedanti-IL-2 polyclonal antibody (KA0276; 1:100; Abnova) at $37^{\circ} \mathrm{C}$ for $60 \mathrm{~min}$. Subsequently, avidin-biotin-peroxidase complex working liquid was added at $37^{\circ} \mathrm{C}$ for $30 \mathrm{~min}$. Finally, $3,3^{\prime}, 5$, 5 -tetramethyl benzidine (TMB) was added at $37^{\circ} \mathrm{C}$ in the dark for $20 \mathrm{~min}$. Following the addition of TMB stop buffer, the plate was read on a microplate reader at $450 \mathrm{~nm}$ to calculate the IL-2 concentration.

Immunohistochemistry. The paraffin sections were dewaxed and dehydrated. They were then treated with $3 \% \mathrm{H}_{2} \mathrm{O}_{2}$ for $10 \mathrm{~min}$. Following the addition of citrate buffer solution, microwave antigen repair and non-immune serum antigen blocking for $20 \mathrm{~min}$, the sections were treated with anti-NF- $\mathrm{kB}$ p65 antibody (cat. no. $8242 \mathrm{~T} ; 1: 200$ ) at $4^{\circ} \mathrm{C}$ overnight. The section was then incubated in biotin IgG antibody (cat. no. ab6720; 1:200) at room temperature for $20 \mathrm{~min}$ and streptavidin-hydrogen peroxide enzyme (cat. no. ab64269; Abcam, Cambridge, MA, USA) solution at room temperature for $20 \mathrm{~min}$. Finally, the section was observed under a microscope (CX41; Olympus Corporation) following DAB coloration, dehydration and sealing. Positive cells exhibited tan-colored staining of the nucleus and cytoplasm close to the nuclear membrane, with tan granular deposits observed. A total of 5 visual fields were randomly selected for the counting of NF- $\mathrm{kB}$ p65-positive cells. The mean value was calculated as the number of positive cells in the rat.

Statistical analysis. SPSS version 15.0 (SPSS, Inc., Chicago, IL, USA) was used to perform two-sample independent t-test for the comparisons of incubation period, weight loss and symptom duration. Fisher's test was performed for morbidity and mortality rate calculation. A $\chi^{2}$ test was used to detect inflammatory infiltrate cell apoptosis, and a t-test was used to compare the number of perivascular inflammatory infiltrate cells, serum IL-2 content and NF- $\kappa B$ p65-positive cell number 
Table I. EAE clinical manifestation and tissue pathologic changes in each group.

\begin{tabular}{|c|c|c|c|c|c|}
\hline Group & Cases & Morbidity (\%) & $\begin{array}{l}\text { Mean highest nerve } \\
\text { function score }\end{array}$ & $\begin{array}{l}\text { Mean onset } \\
\text { time (day) }\end{array}$ & Lesions (n) \\
\hline Control & 10 & 0 & 0 & 0 & 0 \\
\hline EAE & 10 & 100 & $3.36 \pm 0.64$ & $10.13 \pm 0.76$ & $26.21 \pm 0.72$ \\
\hline TWP & 10 & 60 & $2.10 \pm 0.43^{\mathrm{a}}$ & $12.22 \pm 0.81^{\mathrm{a}}$ & $12.41 \pm 0.56^{\mathrm{a}}$ \\
\hline
\end{tabular}

Data are presented as the mean \pm standard error of mean. ${ }^{\mathrm{P}} \mathrm{P}<0.05$, compared with EAE group. EAE, experimental autoimmune encephalomyelitis; TWP, Tripterygium wilfordii glycoside.

in brain tissues. $\mathrm{P}<0.05$ was considered as a statistically significant difference.

\section{Results}

Clinical morbidity rates. In the EAE group, all rats were unwell following feeding with MBP for 10-12 days, with a morbidity rate of $100 \%$. The clinical manifestations included depression, anorexia, hair loss, tail-dragging and weight loss. The data obtained from pathological examination revealed that a large number of inflammatory cells around the blood vessels exhibited cuffing infiltration (Fig. 1). The peak period was 2 days following feeding, with symptoms of hind-limb paralysis and rats exhibiting gatism or an agonal state. The highest symptom score in the model group reached $3.36 \pm 0.64$, whereas no symptoms were observed in the control group. Clinical changes in the TWP group appeared on days 13-16 and the morbidity rate was $60 \%$. The rats exhibited mild symptoms, and the highest score was $2.10 \pm 0.43$ (Fig. 2). Of note, in addition to the different incidence rates between the EAE and TWP group, the highest average neurological function score, average time of onset and number of lesions were statistically different between the two groups $(\mathrm{P}<0.05$; Table I). Numerous inflammatory lesions were identified in the brain and spinal cord, and there was increased monocyte and lymphocyte infiltration around the blood vessels with sleeve-like changes. Gliocyte proliferation resulting in the formation of glial nodules was found in the brain and spinal cord white matter. The number of lesions in the TWP group was significantly lower, compared with the number in the EAE group $(\mathrm{P}<0.05$; Table $\mathrm{I})$. No abnormalities were observed on pathological examination of the control group.

TUNEL detection. The number of TUNEL-positive cells increased significantly in the CNS following the onset of EAE. As demonstrated in Table II, the apoptotic rate of the inflammatory cells around the blood vessels in the TWP group was $32.5 \%$, compared with $16.5 \%$ in the EAE group $(\mathrm{P}<0.01)$. This suggested that TWP induced the apoptosis of cells in the CNS inflammatory infiltrate. A reduced number of inflammatory infiltrate cells were apparent in the TWP group, compared with that in the EAE group $(\mathrm{P}<0.01$; Table II), indicating TWP had a promoting effect on the apoptosis of inflammatory infiltrate cells (Fig. 3).

Effect of TWP on the serum expression of IL-2 in EAE. Compared with the control, serum levels of IL-2 were increased significantly in the EAE and TWP groups. The TWP group

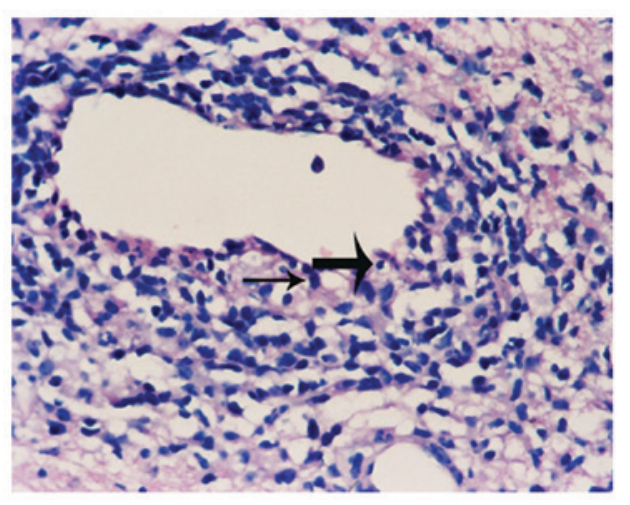

Figure 1. Cuffing infiltration of inflammatory cells around blood vessels. The small arrow points to macrophages with large, kidney-shaped nuclei. The large arrow points to lymphocytes with small, round nuclei stained dark blue with reduced cytoplasm.

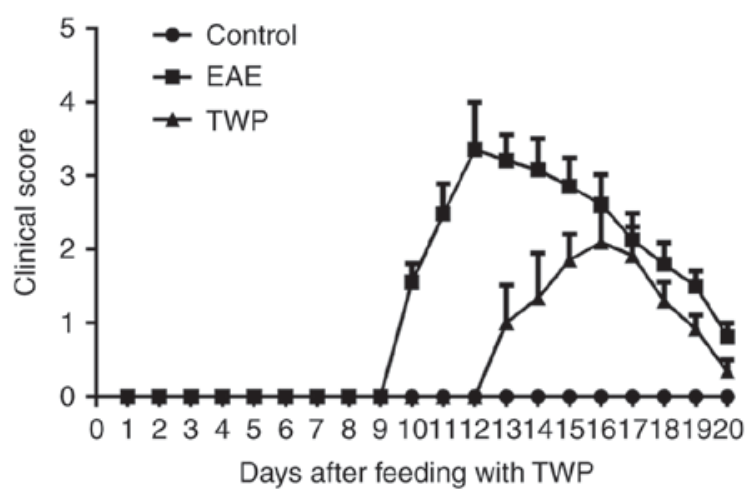

Figure 2. Daily clinical scores following feeding with TWP. EAE, experimental autoimmune encephalomyelitis; TWP, Tripterygium wilfordii glycoside.

exhibited a significantly lower serum level of IL-2, compared with that in the EAE group $(\mathrm{P}<0.05$; Table III), suggesting that TWP suppressed the serum level of IL-2 level in the acute stage of EAE.

Effect of TWP on the expression of $N F-\kappa B$ p 65 in the EAE

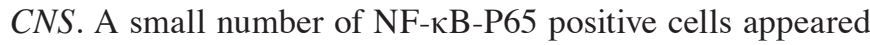
in the CNS in the control group, which were mainly nerve cells and glial cells. A large number of NF- $\mathrm{BP} 65$-positive cells were found in the CNS of the EAE group, and these were mainly located in the white matter, particularly around the blood vessels, in a diffuse distribution. NF- $\mathrm{B}$ p 65 -positive 
Table II. Perivascular inflammatory infiltrate cells number and apoptotic rate in the TWP and EAE groups.

\begin{tabular}{lcccc}
\hline Group & $\mathrm{n}$ & $\begin{array}{c}\text { Inflammatory } \\
\text { infiltrate cells (n) }\end{array}$ & $\begin{array}{c}\text { Apoptotic } \\
\text { cells (n) }\end{array}$ & $\begin{array}{c}\text { Apoptotic } \\
\text { rate (\%) }\end{array}$ \\
\hline EAE & 10 & $103.70 \pm 26.39$ & $17.1 \pm 5.48$ & 16.5 \\
TWP & 10 & $47.40 \pm 36.07^{\mathrm{a}}$ & $15.1 \pm 10.34$ & $32.5^{\mathrm{a}}$ \\
\hline
\end{tabular}

Data of cell numbers are presented as the mean \pm standard error of mean. ${ }^{\mathrm{a}} \mathrm{P}<0.01$, compared with EAE group. EAE, experimental autoimmune encephalomyelitis; TWP, Tripterygium wilfordii glycoside.
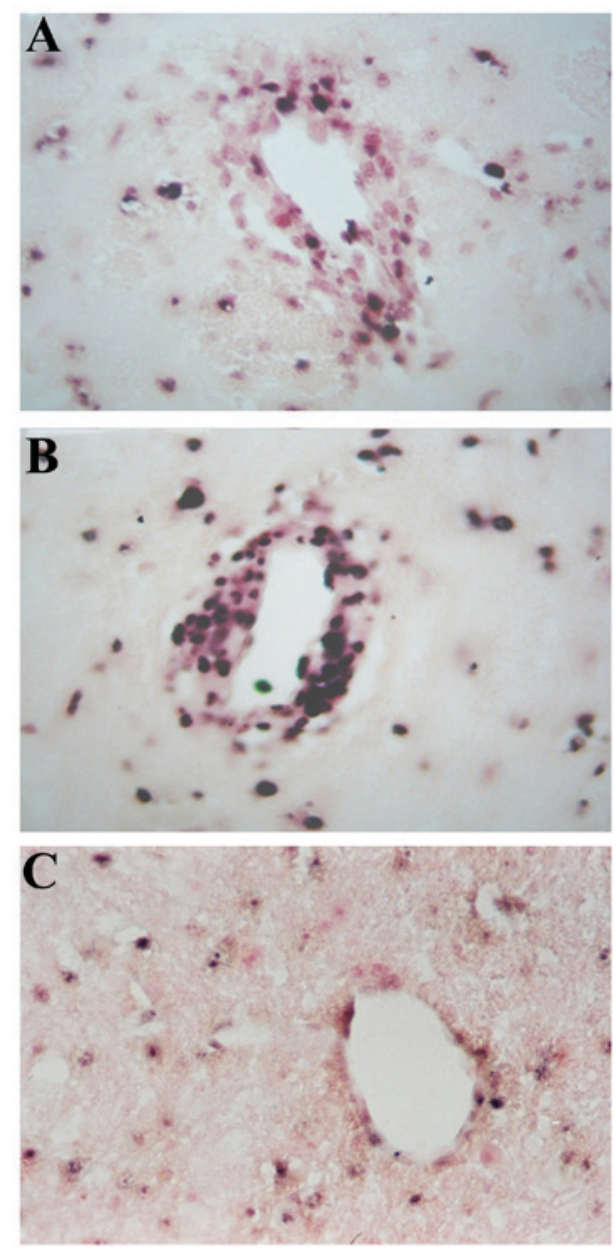

Figure 3. Apoptotic rates of perivascular inflammatory infiltrate cells. (A) Apoptotic rates were low in the EAE group and (B) high in the TWP group. (C) No perivascular inflammatory infiltrate was observed in cells of the control group. (TUNEL staining; magnification, $\mathrm{x} 400$ ). EAE, experimental autoimmune encephalomyelitis; TWP, Tripterygium wilfordii glycoside.

cells were also found in the TWP group, however, the number was significantly lower, compared with that in the EAE group $(\mathrm{P}<0.05$; Fig. 4; Table III). This indicated that TWP inhibited the expression of NF- $\mathrm{kB}$ p 65 in the CNS in EAE.

\section{Discussion}

MS is a form of demyelinating disease in the nervous system, which readily relapses. In patients with MS, $10-15 \%$ are
Table III. Effect of TWP on the expression of NF- $\mathrm{kB}$ p65 and serum level of IL-2 in the central nervous system.

\begin{tabular}{lccc}
\hline Group & Cases (n) & IL-2 (pg/ml) & $\begin{array}{c}\text { NF- } \mathrm{kB} \\
\text { P65-positive cells (n) }\end{array}$ \\
\hline Control & $0 / 10$ & $30.72 \pm 5.89$ & - \\
EAE & $10 / 10$ & $62.56 \pm 8.53^{\mathrm{a}}$ & $72.46 \pm 2.41$ \\
TWP & $7 / 10$ & $41.46 \pm 6.56^{\mathrm{a}, \mathrm{b}}$ & $32.56 \pm 1.56^{\mathrm{b}}$ \\
\hline
\end{tabular}

Data are presented as the mean \pm standard error of mean. ${ }^{\mathrm{a}} \mathrm{P}<0.05$, compared with control group; ${ }^{b} \mathrm{P}<0.05$, compared with $\mathrm{EAE}$ group. EAE, experimental autoimmune encephalomyelitis; TWP, Tripterygium wilfordii glycoside; NF- $\mathrm{B}$, nuclear factor- $\mathrm{B}$; IL-2, interleukin 2.
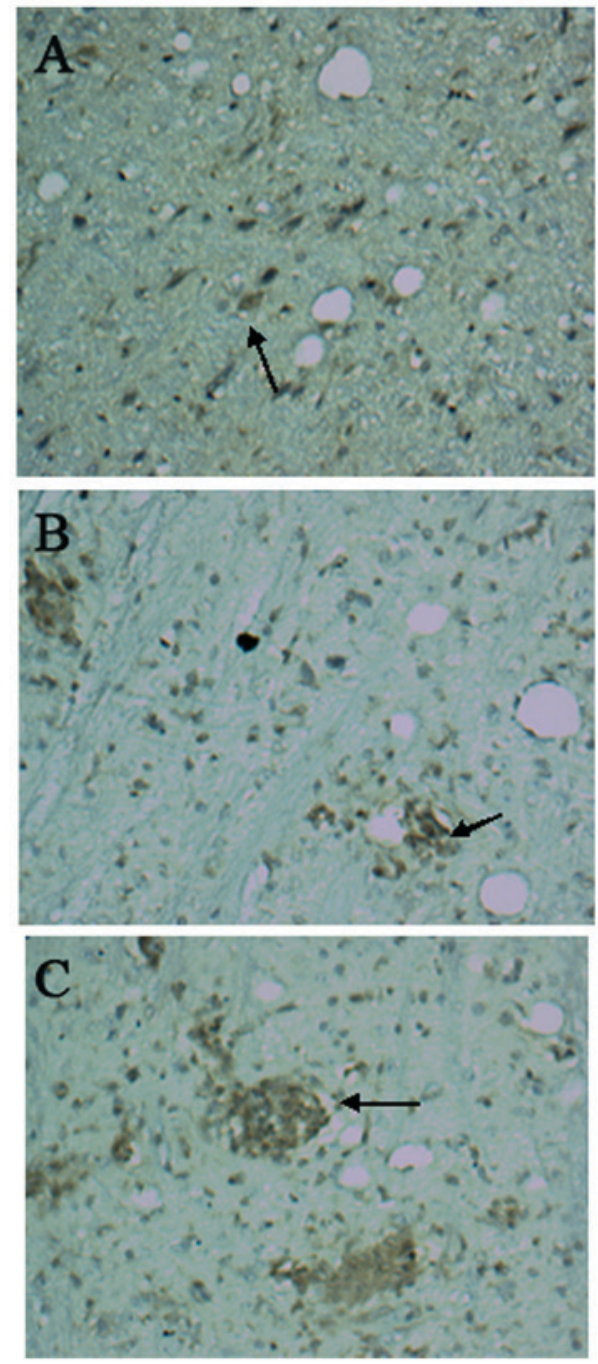

Figure 4. NF-кB p65-positive cells. (A) Small numbers of NF-кB p65-positive cells were distributed in the control group. (B) Few NF- $\mathrm{kB}$ p65-positive cells were observed in the brainstem of the TWP group. (C) Large numbers of NF- $\mathrm{KB}$ p65-positive cells were distributed in the brainstem of the EAE group (DAB staining; magnification, $\mathrm{x} 200$ ). The arrow indicates the NF- $\mathrm{KB}$ p65-positive cells. EAE, experimental autoimmune encephalomyelitis; TWP,

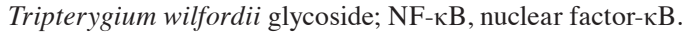

disabled due to its rapid progress and they can succumb to mortality (7). Therefore, the identification and development 
of an effective drug to weaken or terminate this process is a focus of investigations. EAE is widely used to investigate the pathogenesis of autoimmune disease and in the evaluation of immunosuppressive drugs (8). T cell activation and proliferation are key processes in the immune response. The suppression of $\mathrm{T}$ cell activation and proliferation is important in the treatment of EAE (9). NF- $\mathrm{BB}$ is a DNA binding protein, which binds with specific regions of several gene promoters or enhancers, and is involved in the regulation of multiple genes, including cytokines and adhesion molecules closely associated with immune inflammation (10). In addition, $\mathrm{NF}-\kappa \mathrm{B}$ is important in immune cell proliferation, activation and apoptosis. The regulation of $\mathrm{NF}-\kappa \mathrm{B}$ activity directly affects the immune status of the body (11). Tripterygium wilfordii has been commonly used in clinical anti-inflammatory and immunosuppressive treatments in previous years. Experimental and clinical data have confirmed that Tripterygium wilfordii inhibits the immune response at several levels (12).

In the present study, TWP treatment significantly reduced the morbidity (Table I) compared with that in the EAE group, and prolonged the incubation period of Lewis rats in the EAE group. TWP decreased weight loss and alleviated clinical symptoms, suggesting that it had a therapeutic effect on EAE. Cell apoptosis is form of autonomous cell death, which is controlled by genes. It facilitates the elimination of excessive activated $\mathrm{T}$ cells in the immune response and maintains stability. Early in the 1960s, apoptosis was observed in the course of EAE. Schmied et al (13) confirmed that the cell death in EAE was apoptotic, based on morphological observation. The majority of apoptotic cells were activated T cells, with a number of macrophages and oligodendrocytes. As a human autoimmune disease similar to MS, spontaneous remission in EAE is closely associated with inflammatory cell apoptosis in the CNS. As T cells are important in regulating the immune response, treatments able to selectively inhibit $\mathrm{T}$ cell activation or induce $\mathrm{T}$ cell apoptosis have an immeasurable effect on autoimmune diseases (14). As mentioned previously, the effectiveness of Tripterygium wilfordii in the treatment of autoimmune diseases, including rheumatoid arthritis, nephropathy and lupus erythematosus, has been confirmed by a number of clinical and experimental studies. It has been found to induce the apoptosis of activated T cells (15). In the present study, it was found that TWP effectively inhibited the progression of EAE, and it was hypothesized that TWP protects against the disease by promoting the apoptosis of cells in the CNS inflammatory infiltrate to prohibit the unlimited accumulation of inflammatory cells, as shown in a previous study (16). In the EAE model, typical symptoms were usually observed 3 days following onset. Therefore, the animals were anesthetized 3 days following the appearance of clinical symptoms, or were immediately sacrificed if in an agonal state. Between the onset of EAE and the observation of severe clinical symptoms, a large number of $\mathrm{T}$ cells and macrophages moved through the blood brain barrier, gathered in the region around the meninges and blood vessels, and entered the CNS parenchyma. This inflammatory infiltration was parallel with the severity of EAE symptoms, which was inconsistent with a previous finding that the ratio of infiltrated cells and apoptotic cells contributed to the direction of disease (17). EAE was characterized by inflammatory cells around the vessels, which were gathered in a sleeve-type appearance and recognizable under light microscopy. The infiltrated cells consisted mainly of T cells, macrophages and a small number of microglial cells, therefore, inflammatory cells around the blood vessels in the CNS were examined to investigate the entire CNS inflammatory infiltration. In a previous study, it was reported that EAE lesions were most severe in the lumbosacral segment, and were parallel with the severity of EAE symptoms and course of disease (18). Therefore, the spinal cord at the first waist section was selected for observation in the present study. It was found that the number of perivascular inflammatory infiltrate cells was significantly lower in the TWP group, compared with that in the EAE group, and the TUNEL-positive cell percentage was $35.5 \%$ in the TWP group, compared with $16.5 \%$ in the EAE group.

The application of NF- $\mathrm{B}$-suppressing drugs for anti-inflammatory effects has been a focus of investigation (19). It has been reported that triptolide is a potent $\mathrm{NF}-\kappa \mathrm{B}$ inhibitor (20). The present study successfully established an MS animal model of EAE through the treatment of Lewis rats with MBP to overcome the disadvantages of poor repeatability and instability of guinea pig spinal cord homogenate sensitization (21). The experiment showed that the expression of $\mathrm{NF}-\kappa \mathrm{B}$ p65 in the CNS was significantly elevated in the acute stage of the EAE group, and the location of NF- $\mathrm{B}$ p65-positive cells was in accordance with the distribution of inflammatory lesions. This suggested that the activation of $N F-\kappa B$ in the CNS was important in the pathogenesis of EAE. The positive expression of NF- $\mathrm{B}$ p 65 in the CNS decreased significantly following TWP intervention $(\mathrm{P}<0.05)$. ELISA detection showed that the serum level of IL-2 increased $100.03 \%$ in the acute phase of EAE, compared with the normal control, indicating that IL-2 is important in acute EAE. By contrast, TWP reduced the serum level of IL-2 in the fastigium by $33.72 \%$, compared with that in the model group. Based on these results, it was hypothesized that the possible mechanism underlying the effect of TWP in the treatment of EAE was as follows: Under the circumstances of infection, trauma, ischemia or hypoxia stimulation, $\mathrm{NF}-\kappa \mathrm{B}$ in endothelial cells, neurons and glial cells is activated; activated $\mathrm{NF}-\kappa \mathrm{B}$ translocate into the nucleus and binds with NF- $\kappa \mathrm{B}$ loci on target genes, promoting the elevation of proinflammatory cytokine IL-2. This causes damage to the blood brain barrier. Inflammatory cells and cytokines, including IL-2, enter the CNS and activate the immune cells within the CNS expressing NF- $\kappa \mathrm{B}$, which exacerbates the inflammation and demyelination. TWP inhibits the activation of NF- $\mathrm{NB}$ and regulates the expression and activation of inflammatory medium. This reduces the inflammatory effect of TH1 cytokines, including IL-2. TWP also suppresses the proliferation and recruitment of activated lymphocytes in the CNS through CNS inflammatory infiltrate cell apoptosis, which cuts off a series of inflammatory processes to inhibit EAE lesions and relieve the progression. As a mature proprietary Chinese medicine, TWP is low cost and causes fewer adverse reactions. TWP may have a potential effect in nervous system immune disease.

In conclusion, the present study showed that TWP suppressed EAE by inhibiting CNS inflammatory cell infiltration, upregulating apoptosis, and reducing the levels of $N F-\kappa B$ and IL-2. 


\section{Acknowledgements}

This study was supported by the Natural Science Foundation of Fujian Province (grant no. 2008J0308).

\section{References}

1. Diab A, Deng C, Smith JD, Hussain RZ, Phanavanh B, Lovett-Racke AE, Drew PD and Racke MK: Peroxisome proliferator-activated receptor-gamma agonist 15-deoxyDelta(12,14)-prostaglandin $\mathrm{J}(2)$ ameliorates experimental autoimmune encephalomyelitis. J Immunol 168: 2508-2515, 2002.

2. Magnus T, Chan A, Linker RA, Toyka KV and Gold R: Astrocytes are less efficient in the removal of apoptotic lymphocytes than microglia cells: Implications for the role of glial cells in the inflamed central nervous system. J Neuropathol Exp Neurol 61: 760-766, 2002

3. Hao L, Pan MS, Zheng Y and Wang RF: Effect of cordyceps sinensis and Tripterygium wilfordii polyglycosidium on podocytes in rats with diabetic nephropathy. Exp Ther Med 7: 1465-1470, 2014.

4. Zhu J, Cui K, Kou J, Wang S, Xu Y, Ding Z, Han R and Qin Z: Naja naja atra venom protects against manifestations of systemic lupus erythematosus in MRL/lpr mice. Evid Based Complement Alternat Med 2014: 969482, 2014.

5. Ho LJ, Chang DM, Chang ML, Kuo SY and Lai JH: Mechanism of immunosuppression of the antirheumatic herb TWHf in human T cells. J Rheumatol 26: 14-24, 1999.

6. Seger J, Zorzella-Pezavento SF, Pelizon AC, Martins DR, Domingues A and Sartori A: Decreased production of TNF-alpha by lymph node cells indicates experimental autoimmune encephalomyelitis remission in Lewis rats. Mem Inst Oswaldo Cruz 105: 263-268, 2010.

7. Steen K, Narang P and Lippmann S: Electroconvulsive therapy in multiple sclerosis. Innov Clin Neurosci 12: 28-30, 2015.

8. Halmer R, Davies L, Liu Y, Fassbender K and Walter S: The innate immune receptor CD14 mediates lymphocyte migration in EAE. Cell Physiol Biochem 37: 269-275, 2015.

9. Fisher JD, Acharya AP and Little SR: Micro and nanoparticle drug delivery systems for preventing allotransplant rejection. Clin Immunol 160: 24-35, 2015.

10. Kodela R, Nath N, Chattopadhyay M, Nesbitt DE, VelázquezMartinez CA and Kashfi K: Hydrogen sulfide-releasing naproxen suppresses colon cancer cell growth and inhibits NF- $\mathrm{KB}$ signaling. Drug Des Devel Ther 9: 4873-4882, 2015.
11. Nakajima S, Chi Y, Gao K, Kono K and Yao J: eIF2 $\alpha$-independent inhibition of TNF- $\alpha$-triggered NF- $\mathrm{BB}$ activation by salubrinal. Biol Pharm Bull 38: 1368-1374, 2015.

12. Ni L, Zhou X, Ma J, Zhang XM, Li CJ, Li L, Yang DJ, Shao YY, Zhou SB, Zhang TT and Zhang DM: Wilfordonols A-D: Four new norsesquiterpenes from the leaves of Tripterygium wilfordii. J Asian Nat Prod Res 17: 615-624, 2015.

13. Schmied M, Breitschopf H, Gold R, Zischler H, Rothe G, Wekerle $\mathrm{H}$ and Lassmann $\mathrm{H}$ : Apoptosis of T lymphocytes in experimental autoimmune encephalomyelitis. Evidence for programmed cell death as a mechanism to control inflammation in the brain. Am J Pathol 143: 446-452, 1993

14. Lai JH, Ho LJ, Lu KC, Chang DM, Shaio MF and Han SH: Western and Chinese antirheumatic drug-induced T cell apoptotic DNA damage uses different caspase cascades and is independent of Fas/Fas ligand interaction. J Immunol 166: 6914-6924, 2001.

15. Suvannavejh GC, Dal Canto MC, Matis LA and Miller SD: Fas-mediated apoptosis in clinical remissions of relapsing experimental autoimmune encephalomyelitis. J Clin Invest 105: 223-231, 2000.

16. Zhu B, Luo L, Chen Y, Paty DW and Cynader MS: Intrathecal Fas ligand infusion strengthens immunoprivilege of central nervous system and suppresses experimental autoimmune encephalomyelitis. J Immunol 169: 1561-1569, 2002.

17. McCombe PA, Nickson I, Tabi $Z$ and Pender MP: Apoptosis of $\mathrm{V}$ beta $8.2^{+} \mathrm{T}$ lymphocytes in the spinal cord during recovery from experimental autoimmune encephalomyelitis induced in Lewis rats by inoculation with myelin basic protein. J Neurol Sci 139: 1-6, 1996.

18. Behan PO and Chaudhuri A: EAE is not a useful model for demyelinating disease. Mult Scler Relat Disord 3: 565-574, 2014

19. D'Acquisto F, May MJ and Ghosh S: Inhibition of nuclear factor kappa B (NF-B): An emerging theme in anti-inflammatory therapies. Mol Interv 2: 22-35, 2002

20. He JK, Yu SD, Zhu HJ, Wu JC and Qin ZH: Triptolide inhibits NF-kappaB activation and reduces injury of donor lung induced by ischemia/reperfusion. Acta Pharmacol Sin 28: 1919-1923, 2007.

21. Noor NA, Fahmy HM, Mohammed FF, Elsayed AA and Radwan NM: Nigella sativa amliorates inflammation and demyelination in the experimental autoimmune encephalomyelitis-induced Wistar rats. Int J Clin Exp Pathol 8: 6269-6286, 2015. 